\title{
Um ensaio teórico de caracterização objetiva e crítica do conceito de Administração
}

\author{
An objective and critical characterization of the concept of Management
}

Paulo Tromboni de Souza Nascimento ${ }^{1}$

\begin{abstract}
Resumo
Este ensaio busca uma caracterização objetiva e crítica da ideia de administração. Objetiva, porque baseada na resistência que a situação organizacional opõe à atuação do administrador na busca dos resultados mensuráveis, cobrados pelos interlocutores da organização. Crítica, porque, sem desprezar a subjetividade humana, não recorre ao formalismo, nem à noção de racionalidade na construção do conceito de administração. Crítica, também, porque reformula o problema de definição para um de caracterização, supera limitações de boas tentativas anteriores e deixa uma concepção aberta a novas contribuições. O método adotado foi o da análise crítica de conceitos a partir do confronto da literatura dedicada ao tema e desta com outras relevantes e seu exame via situações hipotéticas ilustrativas. A principal contribuição é conjugar as responsabilidades do administrador e seu poder sobre os recursos e interlocução como meios para alcançar resultados vitais à própria constituição e reprodução da organização. Da rede de responsabilidades sociais viriam então o poder do administrador e suas limitações.
\end{abstract}

Palavras-chave: Concepção de Administração. Responsabilidade e Administração. Teoria da Reprodução da Administração. Valores da Administração.

\begin{abstract}
This essay aims at an objective and critical characterization of management. It is objective because it is based on the barriers that the organizational situation puts up against the manager's actions, which seek to achieve measurable results demanded by the stakeholders. It is critical because, without forgetting human subjectivity, it does not require the ideas of formalism or rationality in the construction of the concept of management. It is also critical because it reformulates the definition problem to one of characterization, overcomes limitations of previous good attempts, and leaves room for new contributions. The adopted method was the critical concept analysis. This means to examine the extant literature and then compare it to other relevant literature. Illustrative hypothetical situations also help to clarify issues in concept construction. The main contribution is to put together the managers' responsibilities and his power over resources and stakeholders as means to achieve results essential to the very constitution and reproduction of the organization. From this network of social responsibilities would then come out the manager's power and its limitations.
\end{abstract}

Keywords: Conception of Management. Responsibility and Management. Management Theory and Reproduction. Management Values.

Artigo submetido em 23 de maio de 2013 e aceito para publicação em 11 de fevereiro de 2014.

\section{DOI: http://dx.doi.org/10.1590/1679-39518865}

1 Professor Associado da Faculdade de Economia, Administração e Contabilidade na Universidade de São Paulo. Endereço: Av. Prof. Luciano Gualberto, 908 - sala G 169 - Cidade Universitária, Butantã, CEP 05508-010, São Paulo-SP, Brasil. E-mail: tromboni@usp.br 


\section{Objetivo}

O propósito desta ensaio é caracterizar uma concepção objetiva e crítica de administração. Não se trata de ditar significados. Seria exercício fútil, até porque não há consenso. Ao contrário, o termo é sujeito a pluralidade e controvérsia. Trata-se apenas de esclarecer elementos e relações essenciais a uma concepção objetiva e crítica.

Tal propósito é reconhecida e explicitamente teórico. Bebe na tradição de Barnard (1942), Simon (1997), Thompson (1967), Mintzberg (1979) e tantos outros que se dedicaram à teoria em administração.

\section{Método - a caracterização objetiva e crítica}

Como lembra Wittgenstein (1975), quando trata o significado da expressão "jogo", há termos da linguagem natural que se esclarecem pelo seu uso mais do que por uma fórmula explícita. Wittgenstein (1975) inclusive alerta que talvez nem haja uma fórmula explícita que recubra todo o significado atribuído a um termo pela prática. Wittgenstein aqui adapta a ideia de conceitos primitivos da matemática à compreensão das linguagens naturais. Na matemática, é consenso que noções primitivas não admitem definição explícita. Então, Wittgenstein identificou classes de similaridade de uso de "jogo" para caracterizar um campo de adoção de significado comum e construir protótipos conceituais.

$\mathrm{Na}$ matemática, o sentido das noções primitivas, tais como ponto, reta e plano na geometria euclidiana formal, decorre das relações axiomáticas que se pressupõem entre elas numa determinada estrutura. No fundo, trata-se de seguir conceitualmente a recomendação pragmática de Peirce (1980, p. 5) para alcançar a clareza conceitual: "Considerar os efeitos práticos que possam pensar-se como produzidos pelo objeto de nossa concepção. A concepção desses efeitos é a concepção total do objeto". Na formulação wittgensteiniana, é estudar a estrutura e as propriedades da rede de relações de uso do conceito.

Assim, mesmo sem definir um termo de significado complexo, é possível caracterizá-lo de forma objetiva e crítica. Aqui se busca elencar e ordenar os elementos e relações importantes para a caracterização de um conceito. É a construção de um modelo prototípico do conceito com seus elementos e relações mais importantes, sem tentar uma definição.

Essa, por exemplo, é a abordagem adotada por Maximiano (2000, cap. 1) no sua introdução à administração. Embora realce a definição de Fayol, abaixo reproduzida, acrescenta várias definições de dicionário, discute processos e habilidades necessárias, enfatiza a ação e busca mostrar o espaço discricionário e as principais atividades e habilidades requeridas do gestor. E acaba deixando ao leitor formar a sua própria concepção, embora frisando que certos elementos e relações são cruciais em qualquer modelo de "administração". Também Motta e Vasconcelos (2002) adotam abordagem semelhante. Recentemente, Mintzberg (2009) fez o mesmo.

Essa abordagem busca rigor e clareza no uso de um conceito mesmo sem uma definição explícita. Rigor e clareza, noções realçadas por Descartes $(1979$, p. 37), são, aliás, valores epistêmicos essenciais à construção social da ciência (POPPER,1978). Não é aqui o caso de reentrar na longa polêmica acerca da distinção fato valor que começa em Hume (1980). Para os fins deste ensaio, é suficiente distinguir valores epistêmicos dos demais, como faz Putnan (2004), sem aderir, porém, a sua formulação de que a mera existência de tais valores prejudica a objetividade.

Os valores epistêmicos não são fatos. As pessoas precisam aderir a eles. Caso não o façam, não conseguem intersubjetividade. Ou seja, o debate pode perder-se em divergências subjetivas. Havendo intersubjetividade, cada um pode aferir por si mesmo a objetividade das ideias, ou seja, enfrentar as resistências do objeto 
quando lhe aplica as mesmas ações do interlocutor. Assim, da aceitação da intersubjetividade segue-se a objetividade via a reação à ação de cada um do objeto intersubjetivo.

Nascimento (2007) defende essa concepção de objetividade. Objetivo, portanto, é a resistência à ação de cada um de algo dado para todos. Não pode ser descartada por simples manifestação individual de vontade ou redefinição subjetiva de uma situação. A resistência independe da subjetividade. É por isso que atravessar paredes sempre exige esforço! Não pode ser feito por mera manifestação de vontade. Pelo menos, eu não consigo, nunca vi alguém o fazer, nem ouvi qualquer um alegar que fosse possível, nem apresentar um estudo mostrando tal possibilidade. Essa resistência, aliás, é apenas potencial enquanto o sujeito não age. Agindo, entretanto, a resistência do objeto aparece. O que permite, em princípio, a cada observador constatar para si mesmo se o objeto existe, se atrapalha e como. Cada um independe dos outros nessa constatação. Se o observador discorda do agente, não há um problema epistemológico. Ele pode tentar superar a resistência do objeto e verificar por si mesmo como afeta a ação que observou. Para as ações inúmeras vezes reiteradas e observadas no cotidiano, logo fica claro o que é real e objetivo (para todos) e o que é apenas subjetivo. No cotidiano, a objetividade se baseia no compartilhamento das ações e seus resultados entre os sujeitos, que podem cada um verificar por si mesmos em confronto com a realidade o que é válido ou não.

Algo objetivo, sem dúvida, é intersubjetivo para aqueles que enfrentam sua resistência à ação. Mas a sua condição de intersubjetividade é dada pela sua presença na realidade independente do sujeito. Mesmo que cada um perceba e conceitue o objeto de forma distinta, um núcleo comum permanece nessa caracterização. Do contrário, os sujeitos não reconheceriam o objeto comum na sua intersubjetividade.

Nada disso implica que a subjetividade não provoque efeitos reais. Alguém pode agir por um motivo falso, no qual acredita. Por exemplo, uma pessoa supersticiosa pode falsamente atribuir intenções malévolas a outrem e agredi-lo ou matá-lo. Ou enxergar conexões causais onde só há aleatoriedade. Independente da falsa motivação subjetiva, os resultados da ação permanecem. Porém, a falsidade da motivação alegada só pode ser reconhecida se houver aferição objetiva da ação e de seus resultados.

A aferição dos fatos nem sempre é simples ou acessível a qualquer um. Isso dificulta a verificação objetiva em situações complexas. Em casos importantes, só há o consenso de especialistas nos quais basear uma avaliação objetiva de tais situações. Isso abre espaço para polêmica sobre o que é objetivo numa determinada situação e o que é apenas produto da subjetividade de alguns participantes e observadores.

No contexto organizacional, é a rede de relações sociais que cria uma situação e uma lógica da situação (Popper, 1978) que se opõe à ação do sujeito. Paradoxalmente, como afirma Giddens (1993), essa rede de relações sociais só se evidencia pelas ações que engendra e regula. Ou, como lembra Mingers (2000, p. 1263), "em contraposição às leis do mundo físico, que não são afetadas pela sua própria operação, as relações e estruturas sociais não existem de forma independente das atividades que as realizam".

Talvez seja impossível uma caracterização objetiva do conceito de administração. Seja como for, o único modo de mostrar sua possibilidade é, como na matemática e na lógica, construir e exibir uma caracterização objetiva.

A caracterização objetiva feita aqui se pretende crítica no sentido de não presumir a racionalidade como atributo do conceito de administração. Em especial, exclui-se da caracterização do conceito a racionalidade absoluta da economia tradicional. Porém, mesmo a racionalidade limitada de Simon (1997) não é assumida nessa caracterização. Não significa isso que a racionalidade seja desconsiderada. Ao contrário, é vista como instrumento poderoso da administração. Apenas não é utilizada para caracterizar o conceito de administração, justamente para evitar os elementos subjetivos que emprestaria ao termo, como bem discutido em Nascimento (2009), em relação ao conceito de "organização".

A caracterização também é crítica por não reduzir administração aos seus aspectos formais. Esta concepção inclui as relações sociais informais (particularmente as de poder), como, aliás, não se pode ignorar desde Gouldner (1959). Por fim, a caracterização é crítica, porque parte de contribuições anteriores, reformula o 
problema de definição para um de caracterização, supera limitações de tentativas anteriores e deixa uma concepção aberta a novas contribuições.

Convém alertar que a crítica aqui pretendida não se confunde com a crítica da chamada corrente crítica da administração. Autores nacionais e estrangeiros dessa corrente adotam perspectiva crítica diferente da posta acima. Não estão sob avaliação direta neste texto, nem foram objeto da profunda revisão necessária, embora possa haver implicações indiretas. Tratar deles exigiria outro artigo, pelo que não são aqui citados.

Nesta caracterização objetiva e crítica, explora-se o uso do termo administração e também tentativas anteriores de definição, recorrendo à crítica interna e externa, para descartar nuances e realçar atributos, na esperança de listar um conjunto de características que objetivem o conceito. Ao mesmo tempo se recorre à crítica das concepções anteriores e deixa-se aberta uma porta para futura recaracterização pela crítica da prática, como nos lembra Marx (MARX e ENGELS, 1977) em sua 12 ${ }^{\mathrm{a}}$ tese sobre Feurbach.

O tema abordado aqui é de fundamentos, estabelece uma ontologia. Por isso, às vezes há que recorrer a ilustrações hipotéticas, descontextualizadas, necessárias para esclarecer significados. Se pairar dúvida sobre a legitimidade científica desse recurso, socorro-me com Einstein, mestre em usar experimentos hipotéticos, irrealizáveis, no desenvolvimento teórico. Por exemplo, no tema da equivalência entre um campo de acelerações e um gravitacional, uma ideia central da teoria da relatividade geral. Outro exemplo, pueril, mas teoricamente fértil, é a alavanca de Arquimedes, absolutamente rígida e inquebrável, um ideal irrealizável. À objeção de que tais abstrações não caberiam em administração, recorra-se à Barnard (1942, p. 75-76) quando sugeriu que as abstrações na teoria da organização são análogas às da física.

Vencidas tais preliminares metodológicas, começa-se abaixo com algumas concepções anteriores de "administração" e segue-se com a caracterização do conceito de "organização" baseada numa teoria da sua reprodução. O texto passa pelas responsabilidades e pela axiologia da administração, culminando com a caracterização crítica e objetiva do título. A administração cuidaria da reprodução da organização.

\section{Versões anteriores do conceito de administração}

Se buscarmos o termo "administração", num dicionário, encontraremos algo como "ação de governar ou gerir empresa, órgão público, etc.” (INSTITUTO ANTÔNIO HOUAISS, 2010, p. 17). Já “administrar” seria "exercer mando, ter poder de decisão sobre, dirigir, gerir" (idem). Se buscarmos "gerir", encontraremos no mesmo dicionário (ibidem, p. 388) "exercer mando, ter poder de decisão sobre, administrar, dirigir". "Governar" seria "controlar a formulação e a administração da política"; "dirigir estado ou país"; "ter poder de decisão sobre casa, empresa"; "controlar a velocidade e direção de montaria, veículo ou máquina", dentre outros (ibidem, p. 392). Revela-se assim o núcleo do significado comum em exercer o mando, ou dirigir, ou o poder de decisão sobre as ações de um grupo. Recuperando o sentido de ministrar, isso sugere dizer ao grupo o quê, como, quando e onde fazer.

Para Taylor (1911), administrar é garantir que o trabalho seja realizado com o máximo de eficiência possível. A definição clássica é a de Fayol (1970). Para o autor, as funções administrativas seriam prever, organizar, comandar, coordenar e controlar na busca de eficiência. Modernamente, resulta na ideia de administração como organização, planejamento, direção e controle na busca de eficiência e eficácia.

2 Para evitar confusão entre o conceito e a realidade, este ensaio recorrerá a aspas sempre que estiver considerando um conceito, "organização", por exemplo. Isso porque a mesma palavra é muitas vezes usada para designar a realidade subjacente e ao mesmo tempo certa concepção dessa realidade. 
Simon (1997, p. 1) oferece e critica uma definição anterior de administração como "[...] a arte de conseguir que as coisas sejam feitas". O autor realça que essa definição enfatiza demais a ação e omite a preocupação, para o autor central, com a tomada de decisões que a antecede. A tomada de decisões sobre o que os outros membros da organização vão fazer seria um aspecto crucial da atividade do administrador.

Barnard (1942) também realçou a necessidade de entender a administração no seu contexto organizacional. A função central do executivo é vista como cuidar das atividades de coordenação e decisão para garantir a continuidade da organização (BARNARD, 1942, p. 215).

Uma recente definição de "administração" a conceitua como "[...] reunir e aplicar da melhor forma possível os recursos disponíveis" (TEIXEIRA, SALOMÃO e TEIXEIRA, 2010). Assim, enfatiza a obtenção (... reunir ...) e alocação de recursos e frisa a necessidade de algum critério de desempenho (...da melhor forma possível...). Também introduz algo da problemática administrativa na visão econômica da aplicação de recursos escassos. Ela deixa implícito o papel de tomada de decisões e a negociação necessários para garantir a existência e continuidade da organização, a eficácia de Barnard, realçados por Simon.

Tais definições oferecem um bom ponto de partida, trazendo elementos relevantes para uma concepção de administração. Falta nelas, porém, a clareza da necessidade de constituição e reprodução da organização como fenômeno econômico e social pela ação dos seus diversos interlocutores e integrantes. Embora Barnard e Simon deixem claro de onde viriam os recursos, não esclarecem por que ou como o administrador adquire comando sobre eles. Nem por que tal poder seria concedido. A sua teoria da autoridade - de submissão voluntária dos empregados - parece insuficiente. O que Barnard (1942, p. 158) reconhece ao frisar a inerente e profunda instabilidade do "esquema de incentivos" de seus "sistemas cooperativos". Na visão aqui expressa, a razão dessas omissões é o insuficiente tratamento dado ao contexto social da organização, portanto econômico e institucional, no qual se exerce a administração.

\section{A organização como um sistema social aberto que se reproduz}

Claramente, existe ação coletiva desorganizada. Em geral, ela não gera resultados suficientes para se sustentar. Muitas vezes, o mesmo se passa com a ação coletiva organizada. Nem sempre. Quando gera resultados suficientes para se reproduzir e até se ampliar, cria o campo da ação regular do administrador - a organização. A atividade de administrar se dá no contexto da ação coletiva organizada. Por isso, é preciso esclarecer o sentido de "organização" para chegar no de "administração", como fizeram Barnard (1942) e Motta e Vasconcelos (2002).

Como alertam March e Simon (1958), é mais fácil reconhecer o que é uma organização do que formular uma definição precisa. Tal conceito apresenta semelhança estrutural ao termo "jogo", a saber, de aplicação tão vasta que solicita uma caracterização, já que avesso a uma fórmula definidora explícita. Por isso, recorrer-seá a um protótipo da noção de "organização", adrede preparado por Nascimento (2009), com pequena modificação:

- “organizações não são coisas, nem grupos, mas sistemas sociais abertos de processos e inter-relações envolvendo pessoas que produzem resultados;

- as atividades que integram tais processos se encontram divididas e ordenadas espacial e temporalmente;

- e sua realização exige coordenação, recursos, conhecimentos e habilidades;

- os recursos para um ciclo de operação provêm dos resultados dos anteriores, os quais vêm da inserção num campo ou domínio social; 
- tal domínio, de alta complexidade e incerteza, abriga oportunidades para obter resultados assim como impõe exigências, regras e restrições;

- e tudo isso exige uma hierarquia de comando e um sistema de poder para cuidar dos problemas e conflitos suscitados pelas atividades organizadas e garantir a sua execução ordenada."

Os trechos em itálico foram acrescentados à caracterização de Nascimento (2009) tendo em vista Thompson (1967) e as observações de Pfeffer (2003). O domínio é complexo e incerto e não oferece apenas obstáculos e ameaças. Também é nele que se materializam as oportunidades. Seria, aliás, inexplicável surgir uma organização que consuma recursos num domínio onde só houvesse restrições. E as posições e papéis da organização facilitam a cooperação, mas promovem o conflito.

A caracterização acima é complexa e merece elaboração.

Nos termos de Barnard (1942, p. 81), uma organização é um "[...] sistema de atividades cooperativas conscientemente coordenadas". Dessa definição, Barnard (1942, p. 73) exclui as pessoas, incluindo apenas as relações sociais e atividades. Barnard recorre aqui à distinção que Taylor (1911) introduziu entre as atividades em si e as pessoas que as executam. O que importaria seria reconhecer as atividades e papéis e sua ordenação espacial e temporal. Trata-se de uma abstração que explicita propriedades relevantes e minimiza a importância das pessoas concretas que executam as tarefas.

Com a abstração de papéis e relações sociais, é possível distinguir as pessoas, com suas inúmeras idiossincrasias e virtudes, dos recursos humanos que figuram nas posições abstratas dos organogramas. Também se possibilita entender como as características humanas (racionalidade limitada, interesses e emotividade, por exemplo) podem afetar o desempenho dos papéis na organização. Thompson (1967) postula que um administrador (ou outro agente empoderado) tem liberdade de decidir pela organização. Quando o faz, considera também seus próprios interesses, muitas vezes contrariando os objetivos da organização como um todo ou os interesses de alguns de seus interlocutores. Segue aqui e generaliza a visão das disfunções da burocracia à qual Merton deu origem (BURREL e MORGAN, 2005, p. 184-189).

Em particular, as pessoas diferem dos recursos humanos pelo seu livre arbítrio. Evitando a polêmica filosófica, podemos adotar o livre arbítrio epistemológico (NASCIMENTO, 2006). Nessa posição, o comportamento humano não é redutível a causas sociais observáveis, sendo assim apenas parcialmente influenciável. Isso cria a possibilidade de influenciar fortemente os comportamentos, sem excluir exceções e imprevisibilidade.

Para serem realizadas, as atividades organizadas necessitam de recursos: agentes, ferramentas, insumos, equipamentos, instrumentos, instalações, documentação, serviços, etc. Tais recursos provêm dos resultados anteriores da organização, ou serão repostos com os resultados das atividades correntes. Na caracterização acima, fica claro que os resultados vêm de transações entre os participantes no ambiente. Adota-se aqui a teoria da "economia de incentivos" de Barnard (1942, p. 139), que atribui o funcionamento contínuo da organização às trocas de contribuições entre clientes, empregados e proprietários. As contribuições, ou, quando recebidos, incentivos, seriam monetários, materiais, sociais e ideológicos conforme o tipo de organização e de participante. Simon (1997, p. 140) adotou a mesma ideia sob o nome de "equilíbrio da organização". E acrescentou os fornecedores (Idem, p. 141). Uma visão atual exige um elenco ainda mais diversificado dos públicos envolvidos (por exemplo, terceiros afetados por externalidades).

A ideia de coordenação consciente é desnecessária. O mecanismo de coordenação por ajuste mútuo de Mintzberg (1979, p. 3) já antecipa isso. Contudo, pode-se pensar na coordenação espontânea da ação coletiva, sem necessidade de consciência sequer para as ações de coordenação do líder. Basta observar leoas caçando. Há organização e coordenação, mas a ninguém ocorreria atribuir consciência disso às leoas. No entanto, há uma intenção comum, mesmo se implícita: obter alimento. Um modo de reinterpretar este "conscientemente", de Barnard, é substituí-lo por um resultado esperado da atividade. Nessa formulação, 
intenção não implica consciência de organização e coordenação. Num exemplo ainda mais eloquente, uma ameba é um ente organizado, sem qualquer consciência. A noção de intenção aqui guarda semelhança com a noção de modelo em Holland (1995; 1998).

Um modo de avançar na caracterização é reformular a definição de Barnard de modo pragmático. A organização seria assim um sistema de atividades cooperativas coordenadas para alcançar resultados. Não importaria se a coordenação é consciente ou espontânea. Só se gera resultados.

O que se pode dizer dos resultados da ação cooperativa coordenada? Antes de outra coisa, os resultados precisam contribuir decisivamente para a reprodução do sistema que a promove. No caso das leoas, isso quer dizer ser capaz de alimentá-las e aos outros membros do seu grupo. No caso das empresas e instituições, os resultados devem convencer clientes, patrocinadores ou os próprios membros da organização a fornecer os recursos necessários à continuidade das suas atividades.

O elemento crucial da caracterização proposta aqui é que a organização existe para, através de seus resultados, retirar do domínio onde opera recursos suficientes para sua reprodução. Do contrário, cessaria de existir. A teoria de organização aqui exposta é uma teoria da aplicação dos resultados para pagar as contribuições necessárias à reprodução contínua da organização ou, de modo curto, uma "teoria da reprodução" da organização.

Há um cuidado aqui. A palavra reprodução não vem utilizada na sua acepção biológica de geração de uma prole. No uso deste ensaio, a palavra reprodução designa a repetição de um padrão reconhecível de atividades que caracteriza uma organização. Não se trata, portanto, da reprodução de organismos biológicos. Trata-se da reprodução de padrões em processos e relações sociais. Essa noção de reprodução remonta a Marx e Engels (1977) que a empregaram na compreensão da evolução das sociedades humanas.

Giddens (1993) busca reconciliar a noção materialista destes autores com as vertentes interpretacionistas da ação social. Giddens destaca a importância da linguagem na própria constituição das interações sociais, mas também frisa sua ancoragem nos recursos, condições precedentes e limitações reais da ação. Com isso, limita o alcance da vontade e constrange uma visão subjetivista. Um corolário direto dessa ideia de reprodução social da organização é a ênfase nos resultados da ação coletiva organizada. Essa ênfase também aponta para a incerteza nos resultados da ação social (KNIGHT, 1971), na medida em que reconhece as consequências inesperadas da ação social, cuja importância foi sugerida por Merton (1936) e reforçada por Thompson (1967) e Popper (1978). A ideia importa, porque junto com livre arbítrio epistemológico mostra os limites da previsão em ciências sociais: as reações imprevisíveis de interlocutores e terceiros.

Os resultados, portanto, são essenciais na coordenação de um sistema de atividades. São eles que levam alguém a colocar os recursos necessários à reprodução do sistema de atividades coordenadas: sejam clientes, participantes ou terceiros interessados. Ou seja, a ordenação conjunta espacial e temporal precisa garantir atividades suficientes e adequadamente ordenadas para assegurar os resultados. Além disso, a natureza dos resultados visados restringe a natureza das atividades a serem realizadas e dos recursos necessários. A coordenação precisa, portanto, estabelecer quem faz o quê, com quais recursos, onde e quando, de modo a alcançar os resultados. E, crucial, porque gera conflitos de interesses, o quê e quanto cada contribuinte recebe para fazer a sua parte. Nesse sentido, a coordenação é instrumental. É meio para que as atividades de execução cheguem ao resultado. Isso significa estabelecer as atividades e sua ordenação e zelar pela sua execução segundo essa ordem.

Reprodução de resultados é assim essencial nessa caracterização pragmática, porque uma organização não é um objeto que se possa agarrar. Ela não é tangível e só se realiza como um padrão em atividades que guardam relações reconhecíveis entre elas, mesmo mudando as pessoas que as executam. Excluir-se-ia assim o sistema de atividades que não se repete. A reprodução não precisa ser perfeita. Pode mudar por erro ou intenção. Pode, portanto, fazer-se acompanhar de reorganização, intencional ou não. 
E os resultados esperados não precisam ser mera projeção no futuro. Podem muito bem ter já sido antes observados ou experimentados. A sutileza dessa última observação está em explicar a emergência inconsciente da organização. Emerge naturalmente uma complexa ordem oculta (HOLLAND, 1995). Basta um grupo realizar um conjunto de atividades com um resultado que lhe agrada, mesmo acidentalmente, ou até visando a outros produtos, para se abrir a possibilidade de repetir o padrão de atividades em busca de reproduzir esse resultado fortuito. Para isso, basta a memória de que certo padrão de atividades em certa situação levou a resultados desejáveis: uma lauta refeição no caso das leoas que caçam juntas. Reproduzido o resultado desejável, abre-se ao grupo a possibilidade de repetir o padrão de atividades sempre que desejar.

Nada impede que grupos totalmente distintos observem e imitem o primeiro grupo. Nada impede o primeiro grupo de incluir ou excluir membros. E nada impede o primeiro grupo ou os sucessores de aperfeiçoarem o padrão de atividades para melhorar o resultado. Abre-se aqui um caminho para a organização espontânea que se converte em perene e se auto aperfeiçoa, mesmo sem autoconsciência.

Evidentemente, a capacidade de refletir sobre as atividades e sua ordem pode acelerar e melhorar muito o processo, mas o ponto chave é a possibilidade de emergência espontânea (HOLLAND, 1998). E isso reforça a convicção de que o termo "conscientemente" não precisa constar da definição de "organização". Nascimento (2009) explora outras implicações dessa omissão. Aqui basta frisar que racionalidade e formalismo deixam de ser cruciais para caracterizar "organização". Racionalização e formalização passam a ser instrumentos ao dispor da administração para melhorar o desempenho da organização na busca dos resultados dela esperados pelos seus interlocutores.

\section{A axiologia valorativa da administração}

Se resultados são cruciais na reprodução do objeto social, quais as consequências disso para quem dirige a organização?

Taylor, Fayol e Weber já haviam realçado a importância da eficiência para o administrador. É evidente que, não importa o que se esteja fazendo, usar menos recursos é sempre um critério de bons resultados, porque diminui a pressão de reposição e aumenta a disponibilidade para atrair novas contribuições.

Com a teoria do equilíbrio organizacional, Simon (1997) evidenciou a conexão explícita entre o alcance de resultados, a geração de recursos e a sobrevivência e expansão da organização. Há, assim, um enorme incentivo para premiar a eficiência e toda mudança que traga maior eficiência: continuar e aumentar as recompensas de quem contribui com a organização. Não surpreende o papel central desempenhado pela busca da eficiência na prática administrativa e na reflexão sobre ela.

Mas a reflexão histórica mostra que não se pode contar com um ambiente social estável. E, quando o domínio de ação muda, resultados crescentes exigem que a organização altere suas atividades, seus produtos e serviços, os recursos que utiliza, os mercados com os quais transaciona, as fontes de recursos às quais recorre. Ganha realce o problema da eficácia.

Não é suficiente economizar recursos, é preciso empregar os resultados onde promovam a reprodução ampliada da organização. Num ambiente em permanente e imprevisível mutação, a eficácia deve prevalecer sobre a eficiência. As alternativas são resultados insuficientes e falência.

Por estarem intimamente ligados à reprodução ampliada da organização, os valores da eficácia e da eficiência são definidores do papel da divisão vertical do trabalho. Tornam-se assim os valores axiológicos da administração. 
Porém, a organização é parte de um sistema social mais amplo que lhe fornece os recursos e a legitimidade para operar, reproduzir-se e crescer. Esse meio social difunde e cobra conformidade a outros valores além da eficiência e eficácia através dos vários públicos com os quais a organização interage. Sob pena de criar obstáculos à sua reprodução e crescimento, a organização precisa evitar entrar em conflito com tais valores. $\mathrm{E}$ as exigências neste campo são extensas. Vão desde manter banheiros separados para homens e mulheres até evitar desrespeitar crenças religiosas dominantes. Um deslize para agradar clientes árabes pode levar a um boicote por investidores judeus, ou vice-versa. Desrespeitar a comunidade judicial pode acarretar derrotas constantes nos conflitos legais. Manifestar preconceito de gênero, ou práticas abusivas contra colaboradoras, pode acarretar abandono pelas consumidoras atentas ao tema. Causar problemas ao meio ambiente pode levar a séria perda de reputação e causas judiciais caríssimas.

Mas é fundamental ter clara a ordem de prioridades. Ao administrador, primeiro interessam eficácia e eficiência. Em favor dessas duas, segue-se o respeito aos demais valores do meio circundante. Não é um acidente que grandes empresas mundiais façam propaganda com times e personalidades diferentes em países diferentes, nem que defendam e promovam valores diferentes em culturas diferentes.

A administração é absoluta em sua perseguição da eficácia e eficiência, mas é relativista sobre outros valores. Atende aqueles que o ambiente social demanda, desde que não comprometam a eficácia na reprodução da organização.

Eficácia, eficiência e outros valores são um modo abstrato de falar dos propósitos objetivos da administração. Um modo concreto é lembrar que há públicos cobrando o exercício de tais valores. Ou seja, a administração responde às demandas dos públicos com os quais a organização se relaciona. São as responsabilidades da administração.

\section{A responsabilidade da administração}

De acordo com Barnard (1942), a primeira função do executivo é manter a organização funcionando, ou seja, garantir que haja pessoas suficientes operando recursos suficientes para conjuntamente reproduzir o padrão de atividades que leva aos resultados esperados. Trata-se de exigência fundamental. Sem ela, a organização fenece e deixa de ser relevante.

Assim, as práticas administrativas formam um sistema articulado, cujo sentido final é contribuir para o desempenho eficiente e eficaz das demais atividades da organização. Tais práticas adquirem por isso sentido objetivo como frisado em Nascimento $(2007 ; 2008)$. Se atrapalham, são logo eliminadas. Se não contribuem, consomem recursos, reduzindo o desempenho. De novo, tendem à eliminação, muito embora possa haver inércia maior ou menor e até resistência. É por formarem um sistema que contribui para os resultados da organização e promove a coesão da coalizão que sustenta a ordem vigente, que tais práticas administrativas têm um significado objetivo, independente da subjetividade dos indivíduos que as implementam.

Dessa concepção, emerge diretamente uma variante da teoria da economia de incentivos de Barnard (1942) ou do equilíbrio da organização de Simon (1997). Trata-se de um modo requintado de dizer que os clientes (ou patrocinadores; em alguns casos, os próprios participantes) precisam aceitar pagar pelos produtos o montante suficiente para cobrir os pagamentos diretos e indiretos que a organização precisa fazer a todos que contribuem para a obtenção dos resultados.

Os autores fizeram algumas simplificações em sua formulação inicial. Tais aspectos podem e precisam ser relaxados para dar conta da real complexidade das relações entre os diversos tipos sociais que contribuem para formar as organizações. 
Em primeiro lugar, Barnard e Simon separaram a decisão de contribuir com a organização, particularmente no caso de empregados e gestores, das decisões e ações quando da execução das atividades da organização. Para fins analíticos, tal separação pode ser útil. E até há situações nas quais tal separação possa ser uma boa aproximação do modo de decidir e agir dos empregados e dirigentes de uma organização. Porém, tal separação prejudica o entendimento da operação das organizações em geral.

Como frisa Gouldner (1959), a organização é um sistema aberto. Seu grau efetivo de fechamento às perturbações do ambiente depende de muitos fatores fora do controle da sua administração. Mas há alguns controláveis, ou ao menos influenciáveis, os fatores estratégicos de Barnard. Thompson (1967, cap. 3) chama de campos ou domínios de ação da organização ao conjunto do ambiente no qual a organização opera. E nesse campo ou domínio se destacam os múltiplos interlocutores e agentes individuais, organizacionais e institucionais com os quais a organização se relaciona e de quem depende. Para Thompson (1967, p. 6), "os melhores planos dos administradores têm consequências não intencionadas e são condicionados ou atrapalhados por outras unidades sociais - públicos e organizações complexas - das quais a organização depende".

Uma década mais tarde, Pfeffer e Salancik (2003) destacaram o controle externo sobre as organizações decorrente de sua dependência de recursos provenientes desse ambiente. E a análise estratégica, com Porter (1979), não só realçou essas restrições (e oportunidades) externas às decisões e operações das organizações como também chamou a atenção para as oportunidades de manobrar as interações com os cinco tipos de interlocutores do ambiente operacional da empresa. Na gestão de operações, ganhou grande destaque a ideia de se posicionar na cadeia de suprimentos e de a controlar ou, ao menos, influenciar.

Mas a análise estratégica de Porter recua em relação a Thompson (1967) e Pfeffer e Salancik (2003) porque subestima outros fatores igualmente importantes para o desempenho empresarial e para entender o ambiente que afeta o dirigente das organizações. Por exemplo, o mercado de trabalho, mormente o de especialistas e altos dirigentes, e o mercado financeiro, tanto monetário quanto de títulos. A ninguém escapa o papel que bancos e investidores têm em moldar as decisões das organizações. Tampouco Porter distingue entre serviços de infraestrutura e os de outros fornecedores da cadeia de suprimento, o que tem enorme impacto na competitividade internacional, um tema vital no atual ambiente globalizado.

Por último, começando com os movimentos trabalhistas europeus, ainda no século XIX, que colocaram os temas sociais na agenda de conflitos das organizações, passando pelos anos sessenta, com os movimentos de consumidores liderados por Ralph Nader e continuando com a emergência dos movimentos ambientalistas e a recente ênfase em responsabilidade social corporativa, o público em geral passa a ser interlocutor regular das organizações com muitas exigências que não podem ser simplesmente ignoradas.

Aliás, a influência das organizações profissionais é silenciosa, mas nem por isso menos importante. Advogados, engenheiros, médicos e outros profissionais, de cujos quadros saem grande parte dos executivos, gerentes e conselheiros de administração das organizações, sem falar de sua participação na política e em órgãos de governo, e cuja atividade é cada vez mais vital ao alto desempenho organizacional, exercem enorme influência individual e coletiva nos processos decisórios internos e no entorno das organizações.

O que emerge dessas singelas observações é um complexo campo de pressões e de demandas a ser atendido pelas organizações, o que define as responsabilidades diretas de seus altos dirigentes assim como molda as pressões sobre a média e baixa gerência. É vital frisar que o dirigente não pode ignorar tais demandas ao seu bel-prazer. Se o fizer, perderá rápido a função de mando. Um caso emblemático a esse respeito foi o de Steven Jobs, demitido por desempenho insuficiente da função de dirigente máximo da Apple, a empresa que criou. E o seu retorno se deu para melhorar o desempenho junto aos clientes, com o que aumentou a capacidade de atender os diversos outros públicos, e não pelo fato de ser sócio do negócio. A separação entre propriedade e gestão é inclusive institucionalmente consagrada em legislação específica e reforçada por obrigações legais e contratuais. $\mathrm{O}$ dirigente pouco atento às suas responsabilidades, não se arrisca apenas a perder o poder. Pode acabar condenado e apenado judicialmente. 
A pressão da responsabilidade sobre o executivo é enorme.

O que a discussão acima realça é o enorme esforço que os gerentes têm de empreender para atender os diversos públicos envolvidos, desincumbindo-se assim de suas responsabilidades. E muito embora exista a fraude e até possa ser bem-sucedida por algum tempo, rápido o público fraudado se vê prejudicado e reage. Primeiro, isso prejudica a reputação do administrador fraudador, o que diminui sua capacidade de firmar compromissos com outros públicos. Se esse público tem poder, pode excluir o administrador, obrigá-lo a restituir suas perdas e até puni-lo com prisão ou exclusão do mercado de executivos. Outras vezes, as vítimas de fraude não têm poder suficiente. Se o administrador fraudador insistir, estimulado pelo sucesso na fraude, cedo ou tarde encontrar-se-á com um público ou interlocutor poderoso que o derrubará. Outras vezes, a acumulação de desgastes o incapacita para obter o desempenho que outros interlocutores poderosos lhe cobram, o que também acarreta sua substituição. Em ainda outras histórias, o cúmulo de fraudes ocasiona a perda de credibilidade e condenação judicial. Enfim, embora haja ocasiões em que o fraudador seja bemsucedido, a fraude sistemática gera adversários até derrubar o administrador. Promessas não cumpridas têm efeito semelhante, embora atenuados e de modo mais lento.

O outro lado da moeda da responsabilidade é o poder real de direcionar os fluxos de recursos e custos, benefícios e sacrifícios, na organização. Barnard (1942) e Simon (1997) relativizaram o poder do executivo, frisando o livre arbítrio das pessoas, ou seja, em última análise, só se submeteria quem quisesse. De fato, há graus de benefícios e sacrifício e todos precisam sobreviver e viver, o que empresta grande peso ao poder dos executivos e gerentes. Além disso, só raramente um dirigente perde o poder quando desagrada um interlocutor isolado ou mesmo uma coleção deles de menor capacidade de prejudicar o desempenho global da organização. Até porque quem pode excluí-los precisa reunir o poder suficiente, precisa reconhecer os desafios enfrentados pela organização e precisa de alternativas melhores, o que favorece a inércia. E, vital ao fim e ao cabo, com raras exceções, o executivo pode sempre substituir alguém que não se submete às suas determinações. Como destacou Pfeffer (2002), o poder, na sua encarnação de dependências e interdependências, é um tema central para entender a forma, as decisões e as ações das organizações.

Portanto, o executivo tem poder real. Mas, do ponto de vista dos interlocutores, legítimo apenas para alcançar resultados que melhorem a situação da organização.

Aqui Thompson (1967) ofereceu uma ideia central ao lembrar que o executivo também tem livre arbítrio e interesses. A segunda parte de seu livro clássico é dedicada a gerar hipóteses sobre como os interesses pessoais do executivo (carreira, renda, outros) conjugados às incertezas que cercam a organização afetam o seu comportamento no exercício do poder discricionário que lhe é concedido pela organização. Ainda mais intensamente, como lembram Bower, Doz e Gilbert (2005), quando a organização erra na estrutura de incentivos que apresenta ao executivo para promover a alocação de recursos.

Em resumo, há um núcleo forte na proposição de Barnard (1942) e Simon (1997) sobre o papel da administração de promover o equilíbrio da organização. Há subestimação, contudo, da abrangência das suas responsabilidades. Também aceitam uma divisão artificial entre a decisão de participar, sempre aberta, e as decisões no exercício das atividades organizacionais, subestimando o papel dos interesses individuais e grupais nas decisões e ações nos cargos. Por outro lado, subestimam o poder de mando da administração. Esquecem que a maioria dos membros da organização pode ser facilmente substituída e que as punições e recompensas são controladas pela administração. E há ainda a competência efetiva dos administradores (é difícil demitir quem dá resultados), sua disposição para aceitar a pressão e a responsabilidade, inclusive legal, e a legitimação concedida pelo sistema social mais amplo.

\section{Conclusões e implicações}

Como concepção crítica e objetiva de "administração", a discussão acima sugere elencar as características abaixo: 
- uma profissão que cultiva a eficiência e a eficácia na busca de resultados

- cuja distribuição permite à organização cumprir suas responsabilidades com seus integrantes e demais interlocutores,

- sobre os quais exerce limitado poder real,

- através do seu controle sobre os recursos, atividades e comunicações,

- constituindo e reproduzindo a organização.

O destaque para os valores da eficiência e eficácia aparece pelo papel da administração de assegurar recursos suficientes para retribuir as contribuições necessárias, assim como recompensar as mais eficazes na reprodução organizacional. De fato, eficiência e eficácia são os valores pelos quais os administradores são avaliados no desempenho profissional.

A cobrança de outros valores é relativa ao impacto do contexto social sobre a eficiência e eficácia. Em cada sociedade, ou em campos distintos da atividade em sociedades complexas, e até mesmo em organizações específicas, o conjunto de valores relevantes varia. Por isso não é necessário que tais valores entrem na caracterização do conceito de "administração", embora respeitá-los seja consequência imediata. Tal respeito coloca, entretanto, o problema de conciliar conflitos valorativos, por vezes contraditórios, nas e entre as sociedades e seus públicos e grupos.

A segunda característica diz por que a administração tem poder de mando. É para atender a uma coalizão suficientemente abrangente de interesses, diferencialmente representados.

Já o terceiro ponto explicita e reconhece o poder da administração sobre integrantes e interlocutores da organização, mas também suas limitações.

A quarta característica também é necessária. Sem ela, a administração não poderia organizar e coordenar a ação coletiva na busca de resultados. Isso exige tanto o poder sobre os recursos internos, que incluem pessoas, portanto interlocução interna, como influência sobre os interlocutores externos, a qual é obtida com maior ou menor habilidade no uso dos recursos da organização. Por outro lado, a característica emerge da própria atividade de alocar recursos aos diversos contribuintes para o desempenho organizacional, como sugere a teoria do equilíbrio de Barnard (1942) e Simon (1997).

A última característica é a crucial, porque revela a conexão entre resultados, poder e a própria constituição e reprodução da organização.

Uma clara limitação da abordagem aqui adotada é a restrição do debate aos clássicos. Em particular não se tratou da corrente crítica em administração, a qual mereceria talvez um trabalho específico. Mas é uma limitação deliberada. Trata-se da busca de alternativas para caracterização do conceito de "administração" que fujam dos termos atuais de debate. A abordagem de caracterização do conceito não se envolve na discussão do mérito de definições particulares para propósitos particulares. Apenas recorda que qualquer definição seja para fins teóricos e investigativos particulares, seja para a prática efetiva, cedo ou tarde precisará ser reconciliada com um conjunto de características mínimo, crítico e objetivo.

Outra limitação é lidar com organizações de existência contínua indefinida. Não se cuida aqui de organizações deliberadamente temporárias como projetos ou negócios destinados à liquidação. Sem essa distinção, não se pode sustentar uma teoria da reprodução da organização como uma teoria da administração. Parece claro, contudo, que, por trás de organizações temporárias, sempre há indivíduos ou uma ou mais organizações no sentido anterior dando suporte e destinatárias dos seus resultados. Indivíduos podem substituir organizações, mas raramente são esses os casos mais importantes. Abre-se de qualquer modo uma indagação sobre como se articulam os dois modos de tratar a concepção de administração, a saber: nas organizações de duração indefinida e nas temporárias. Uma sugestão deste texto é que nas temporárias os 
propósitos de Barnard ganham destaque. Objetivos conscientes e explícitos colocam os resultados esperados por indivíduos ou pelas organizações instituidoras e patrocinadoras de negócios, projetos e forças tarefas temporárias. Trata-se de resultados, mas não necessariamente de sua reprodução. Racionalidade e formalização ganham destaque.

Mais uma limitação do texto é não distinguir explicitamente a alta gerência da média e baixa. Nem o pessoal de staff e de linha. Tampouco a gerência geral de uma unidade da gestão funcional. Nestes casos, o poder de mando é restringido a um domínio de atividades, e as pressões do ambiente são fortemente filtradas por um superior hierárquico e interlocutores internos, sejam gerentes ou membros influentes da organização. Para alguns integrantes dessas funções e cargos, há pressões externas também. Por vezes, como no caso de gerentes de marketing são até pressões dominantes. Mas são ambientes mais delimitados e com pressões internas a elas se contrapondo. Nestes casos, o ambiente administrativo interno é fonte de significativas pressões sobre o administrador.

\section{Referências}

BARNARD, C. I. The functions of the Executive. Cambridge, MA: Harvard University Press. 1942.

BOWER, J. L.; DOZ, Y. L.; GILBERT, C. G. Linking Resource Allocation to Strategy. In: ; GILBERT, C. G. (Eds.). From Resource Allocation to Strategy. New York: Oxford University Press, 2005.

BURREL, G.; MORGAN, G. Sociological Paradigms and Organisational Analysis. Burlington, USA: Ashgate Publishing Limited, 2005.

CYERT, R. M.; MARCH, J. G. A Behavioral Theory of the Firm. Englewood. New Jersey: Prentice Hall, Inc., 1963.

DESCARTES, R. Discurso do Método. 2. ed. Tradução de J. Guinsburg e Bento Prado Jr. Coleção Os Pensadores. São Paulo: Editora Abril Cultural, 1979.

FAYOL. H. Administração industrial e geral. 8. ed. em português. São Paulo: Editora Atlas S.A., 1970.

GIDDENS, A. New rules of the sociological method. 2. ed. Stanford, CA: Stanford University Press, 1993.

GOULDNER, A. W. Organizational Analysis. In: MERTON, R. K.; BROOM, L.; COTTRELL JR., L. S. (Eds.). Sociology Today: Problems and Prospects. American Sociological Association, 1959.

HOLLAND, J. H. Hidden Order - How Adaptation Builds Complexity. New York e outras: Addison-Wesley Publishing Company, 1995.

Emergence - From Chaos to Order. Cambridge: Perseus Books, 1998.

HUME, D. Investigação sobre o Entendimento Humano. Coleção Os Pensadores. São Paulo: Abril Cultural, 1980.

INSTITUTO ANTÔNIO HOUAISS. Míni Houaiss - Dicionário de Língua Portuguesa. $4^{\mathrm{a}}$ edição revista e aumentada. Rio de Janeiro: Editora Moderna Ltda, 2010.

KNIGHT, F. H. Risk, uncertainty and profit. Chicago: The University of Chicago Press, 1971. (Originally published by Houghton Mifflin Company in 1921).

MARCH, J. G.; SIMON, H. A. Organizations. New York: John Willey \& Sons, Inc., 1958. 
MARX, K.; ENGELS, F. A ideologia alemã. (Trad.) De José Carlos Bruni e Marco Aurélio Nogueira. Do original alemão Die Deutsche Ideologie. Dietz Verlag. Berlin. 1973. Editorial Grijalbo Ltda. 1977.

MAXIMINIANO, A. C. A. Introdução à Administração. 5. ed. São Paulo: Atlas., 2000.

MERTON, R. K. The Unanticipated Consequences of Purposive Social Action. American Sociological Review, v. 1, p. S 894-904, December, 1936.

MINGERS, J. The contribution of critical realism as an underpinning philosophy for OR/MS and systems. Journal of Operations Research Society, n. 51, p. 1256-1270, 2000.

MINTZBERG, H. The Structuring of Organizations - A Synthesis of the Research. New Jersey: Prentice Hall, Inc. Englewood Cliffs, 1979.

Managing. San Francisco: Barret-Koeller Publishers Inc., 2009.

MOTTA, F. C. P.; VASCONCELOS, I. F. Teoria Geral da Administração. São Paulo: Thomson, 2002.

NASCIMENTO, P. T. S. O livre arbítrio epistemológico na administração. Organização \& Sociedade, v. 13, n. 38, p. 31-44, Jul./Set., 2006.

. A Interpretação Objetiva na Administração. Anais do Enanpad. XXXI Encontro da Anpad, Rio de Janeiro, 22 a 26 de Setembro de 2007. Anpad. Rio de Janeiro, RJ. 2007.

. O Sentido Objetivo da Prática Administrativa. Cad. EBAPE.BR, v. 6, n. 1, p. 1-17, 2008.

. Organização: Critérios para uma Concepção Crítica e Objetiva. Cad. EBAPE.BR, v. 7, n, 4, p. 558-574, 2009.

PEIRCE, C. S. Conferências sobre o pragmatismo. In: Peirce F. Coleção Os Pensadores. São Paulo: Ed. Abril Cultural, 1980.

PFEFFER, J. Introduction to the Classic Edition. In: ; SALANCIK, G. R. The External Control of Organizations - A Resource Dependence Perspective. Stanford Business Classics. Stanford, Ca., USA: Stanford University Press, 2003. Original de 1978.

POPPER, K. R. A lógica das ciências sociais. In: CHACON, V. (Org.). Lógica das Ciências Sociais. Rio de Janeiro: Editora Universidade de Brasília. Edições Tempo Brasileiro, 1978.

PORTER, M. E. How competitive forces shape strategy. Harvard Business Review. March-April. 1979.

PUTNAN, H. The Colapse of The Fact/Value Dichotomy and Other Essays. Cambridge: Harvard University Press, 2004.

SIMON, H. Administrative Behavior - A Study of Decision-making Processes in Administrative Organizations. 4. ed. New York: The Free Press, 1997.

TAYLOR, F. W. The Principles of Scientific Management. 1911.

TEIXEIRA, H. J.; SAlOMÃO, S. M.; TEIXEIRA, C. J. Fundamentos de Administração - A busca do essencial. Elsevier Editora Ltda. 2010.

THOMPSON, J. D. Organizations in action - social science bases of administrative theory. New Brunswick (USA): Transaction Publishers, 2006 (original 1967). 
WEBER, M. Economia e Sociedade - Fundamentos da sociologia compreensiva. (Trad.). Regis Barbosa e Karen Elsabe Barbosa. Revisão Técnica de Gabriel Cohn. São Paulo: Editora UnB, 2004.

WITTGENSTEIN, L. Investigações Filosóficas. Coleção Os Pensadores. São Paulo: Abril Cultural, 1975. 